Psychology of Language and Communication 2017, Vol. 21, No. I

DOI: $10.1515 /$ plc-2017-0019

IZABELLA HAERTLÉ

SWPS University of Social Sciences and Humanities

\title{
DOES GRAMMATICAL GENDER INFLUENCE PERCEPTION? A STUDY OF POLISH AND FRENCH SPEAKERS
}

\begin{abstract}
Can the perception of a word be influenced by its grammatical gender? Can it happen that speakers of one language perceive an object to have masculine features, while speakers of another language perceive the same object to have feminine features? Previous studies suggest that this is the case, and also that there is some supra-language gender categorisation of objects as natural/feminine and artefact/masculine. This study was an attempt to replicate these findings on another population of subjects. This is the first Polish study of this kind, comparing the perceptions of objects by Polish- and French-speaking individuals. The results of this study show that grammatical gender may cue people to assess objects as masculine or feminine. However, the findings of some previous studies, that feminine features are more often ascribed to natural objects than artifacts, were not replicated.
\end{abstract}

Key words:Linguistic Relativity, grammatical gender, arbitrariness of grammatical gender, femininity, masculinity, Generalised Linear Mixed Model regression (logistic GLMM)

\section{Introduction}

Linguistic Relativity theory originates in the works of Sapir (1929) and Whorf (1956). It proposes that each language contains the worldview of its associated culture, mirroring the experience of the community that uses the language and guiding their way of perceiving reality. "We see and hear and otherwise experience very largely as we do because the language habits of our community predispose certain choices of 
interpretation". The suggestion that language significantly influences thought was initially widely criticised, but has recently come back into favour, especially in its weaker forms, and has yielded interesting results - including evidence from neuroimaging studies (e.g. Boutonnet, Athanasopoulos, \& Thierry, 2012; for review see: Thierry, 2016).

Researchers have demonstrated the role of language in the perception of time (Boroditsky, 2000, 2001, 2010), colour (Thierry et al., 2009; Winawer et al., 2007), spatial cognition (Bowerman, Choi, McDonough, \& Mandler, 1999; Gentner \& Loftus, 1979; Landau \& Jackendoff, 1993; Levinson, Kita, Haun, \& Rasch, 2002; McDonough, Choi, \& Mandler, 2003), the perception of motion (Athanasopoulos et al., 2015; Czechowska \& Ewert, 2011), attention and information processing styles (Rhode, Voyer, \& Gleibs, 2016), the perception and memory of events (Boroditsky, Ham, \& Ramscar, 2002; Fausey \& Boroditsky, 2010; Loftus \& Palmer, 1974; Scholl \& Nakayama, 2002), and even constructing agency, including attending to and remembering the agents of events (Choi, 2009; Fausey \& Boroditsky, 2010a; Fausey \& Boroditsky, 2011; Fausey, Long, Inamori, \& Boroditsky, 2010).

One specific aspect of language that may influence perceptions of reality is grammatical gender. Various cultures attribute grammatical gender to words based on various criteria, often seemingly impossible to explain with logic. Does the grammatical gender or class ascribed to a given noun influence the way we perceive it? Is there a supra-language conceptual gender categorisation of objects that is culturally universal, and not as arbitrary as grammatical gender?

One of the first researchers to address these questions was Ervin (1962). In her study, Italian-speaking subjects were asked to assess artificial words that had suffixes typical of either the masculine or feminine grammatical gender in Italian, on scales of properties that were stereotypically masculine or feminine. It turned out that they associated the artificial words with masculine and feminine suffixes with characteristics that were more masculine and more feminine, respectively.

Mullen (1990) showed that English-speaking children are more likely to attribute feminine grammatical gender to natural objects and masculine gender to artifacts. It was theorised that such a categorization of objects stems from the division of the roles that men and women have in society: women are seen as mothers, who give life and nourish, and so anything natural (fruit, vegetables, plants, animals) is associated with the feminine gender; men create and use tools, hence the association of masculine features with artifacts. A study by Konishi (1993) comparing German and Spanish speakers revealed that both groups assessed masculine nouns present in their language as being of higher potency, a trait stereotypically considered masculine (Bem, 1993), than feminine nouns. These results suggest that grammatical gender may not be an entirely arbitrary category.

1 Whorf, B. L., Carroll J. B. (1956). Language, Thought and Reality: selected writings, 207-219. MIT Press. 
In work by Rączaszek-Leonardi (2010), one group of Polish and Italian speakers were asked to attribute adjectives to objects presented either as words or photographs. Another group then decided which of these adjectives were more feminine or masculine. For all objects, in both settings the gender effect was stronger when the adjectives had the same gender as the objects to which they were assigned. This effect was stronger in Polish than in Italian, even though Polish has three gender categories (masculine, feminine, and neuter), while Italian has only two (masculine and feminine). This contradicts a previous study, which showed this effect to be weaker in languages with more than two categories of grammatical gender (Vigliocco, Vinson, Paganelli, \& Dworzynski, 2005). The correlation between the two languages was significantly stronger for animals than for artifacts.

This was in line with an earlier study by Boroditsky and Schmidt (2000), where a list of 50 animals and 80 artifacts was constructed in Spanish and German, and a correlation coefficient was calculated between their grammatical genders. Here, too, grammatical gender was more congruent between the languages for animals than for artifacts. A group of English speakers was then asked to intuitively attribute gender to the same objects. The English speakers' results were highly correlated with the German and Spanish language, but only with regards to nouns describing animals. No such relationship was observed in the case of artifacts.

The same study (Boroditsky \& Schmidt, 2000) revealed that bilingual subjects found it easier to remember noun-name pairs when the grammatical gender of the noun in their native language was congruent with the gender of the name, which was not observed when they performed the same task in English. Other researchers (Cubelli, Paolieri, Lotto, \& Job, 2011) showed that Italian and Spanish speakers were quicker to identify whether pairs of stimuli belonged to the same semantic category when they the shared the same gender; the same was not true for English participants. These results seem to be evidence of an interference effect, which suggests that grammatical gender is perceived somewhat automatically, affecting attention and processing.

In a study by Sera, Berge, \& del Castillo Pintado (1994), Spanish and English speakers were asked to classify pictures of objects as masculine or feminine. The objects pictured either did or did not have a natural gender. Spanish speakers were significantly cued by the grammatical gender of depicted objects when making that assessment. No such effects were observed for English speakers, in whose language grammatical gender practically does not exist. In a variant of the experiment where pictures were captioned with words (including their gendered articles in the case of Spanish), both language groups classified natural objects as feminine more often than artifacts, even if the grammatical gender was masculine in their language. This, again, speaks 
in favour of the claims that there may exist some supra-language variable influencing the way people attribute gender to objects that do not have a natural gender.

However, it should be noted that subjects in this study were explicitly asked to divide objects into masculine and feminine. Thus, Spanish speakers could have been cued to refer explicitly to grammatical gender, which casts doubt on the potential role of supra-language conceptual variables. Thus, a follow-up experiment was conducted to avoid these direct cues, where participants were told that the experimenters are preparing to make a film in which the characters pictured will speak with a human voice, and had to assign a female or male voice to 30 images of objects (natural objects and artifacts). In the Spanish-speaking group, again, there was a tendency to assign voices congruent with grammatical gender. But, interestingly, in cases where the assigned voice gender was incongruent with the grammatical gender, subjects assigned the masculine voice significantly more often to artifacts than to natural objects. While this may speak in favour of the proposed supra-language conceptual categorisation of objects, it does not allow one to fully accept or reject this hypothesis.

A different study by Boroditsky and Phillips (2003) found results similar to those of Sera, Berge, \& del Castillo Pintado (1994) - German and Spanish speakers chose stereotypically feminine or masculine descriptions of objects in a manner congruent with their grammatical gender. When German-speakers were asked to describe a key (masculine grammatical gender in German), they were more likely to use adjectives such as hard, heavy, metallic, or useful. Spanish speakers describing the same key (feminine grammatical gender in Spanish) used adjectives such as golden, small, shiny, or pretty. In the second experiment, subjects were also asked to assess the level of similarity between images depicting objects and images depicting male or female faces, where the objects had the opposite grammatical gender in German and in Spanish. Both German and Spanish speakers perceived the objects as more similar to the depicted people when the grammatical gender of the object in their language was congruent with the depicted person's sex. This paper's conclusions came under criticism, as it was suggested that the experimental design was such that the participants could have relied on direct linguistic cues, i.e. the words' grammatical gender (Cubelli, Paolieri, Lotto, \& Job, 2011; Vigliocco, Vinson, Paganelli, \& Dworzynski, 2005). Hence, the current study has been designed to limit the possibility that subjects could consciously refer to grammatical gender.

\section{Aims}

The goal of this study was to verify the hypothesis that, in groups of Polish and French speakers, grammatical gender cues the perception of objects. It is an attempt to replicate the earlier study of Sera, Berge, \& del Castillo Pintado 
(1994) (performed with groups of speakers of Spanish and English) as well as to expand upon the work of Boroditsky \& Phillips (2003) (performed with speakers of German, Spanish, and English) with speakers of two other languages (Polish and French). Though Polish and French are somewhat distant languages, one being Slavic and the other Romance, both contain grammatical gender, so results similar to those of the aforementioned studies were expected.

The specific goal of the current study was to verify the following hypotheses:

1. Polish and French speakers ascribe masculine and feminine features to a given object in congruence with the grammatical gender of the noun describing that object in their respective languages.

2. Feminine features are more often ascribed to natural objects than to artifacts.

Two experiments were conducted in order to verify the hypotheses.

Following the study by Sera, Berge, \& del Castillo Pintado (1994), the current study verified whether French and Polish speakers assign masculine and feminine voices to objects (presented as pictures without captions, to avoid direct linguistic cues) in accordance with their grammatical gender. As in the experiments of Boroditsky \& Phillips (2003), words whose grammatical genders are different in the two languages were selected - e.g. the word "house", which is masculine in Polish and feminine in French. In order to avoid direct linguistic cues, this experiment was modified: instead of asking subjects to freely produce descriptions, they were asked to choose from a randomised list of adjectives, either stereotypically male or female (but without grammatical gender), an aspect similar to the procedure of Ervin (1962). The objects presented to the participants in both experiments were divided into two types: natural and artificial (according to Boroditsky \& Phillips, the feminine gender will be more frequently attributed to natural objects than to artifacts in all languages). Words of the neuter gender in Polish were not included in the study.

\section{Experiment 1}

French and Polish speakers were shown a series of images first depicting artifacts and then natural objects whose names are of opposite grammatical genders in French and Polish. In order to verify whether grammatical gender influences the perception of these objects, participants were asked to assign to each object either a female or male voice. In this way, the category of gender was implicit in the study. This made it possible for the attribution of masculine or feminine features to objects to be conceptual, and not cued by their grammatical gender. This experiment was based on the study of Sera et al. (1944) on Spanish and English speakers. 


\section{Participants}

Two groups of twenty native speakers of Polish and French (10 women and 10 men in each group) took part in the study. The Polish-speaking group was mainly composed of students, with a few employees of the University of Warsaw and of the Warsaw School of Economics in Poland. The French-speaking group was mainly composed of students and employees of the Angers and Tours Universities in France. Individuals with two or more native languages were excluded in order to eliminate potential interference from the second language.

\section{Materials}

A total of 20 black-and-white images depicting artifacts (a book, a bell, etc.) and natural objects (a turtle, a banana, clouds, etc.) were selected, such that the grammatical gender of each of these objects was different in Polish and French. A group of 8 Polish-speaking competent judges were asked to define the objects depicted in the images. On this basis, only objects whose names were unambiguous were used. One of the natural objects was removed, as the judges were not in agreement about it. This left 19 images that were used in the study. In order to eliminate additional confounding variables, each participant received the images in a different order. Figure 1 shows a few examples of images used in Experiment 1. Table 1 shows the list of names of objects in both languages.
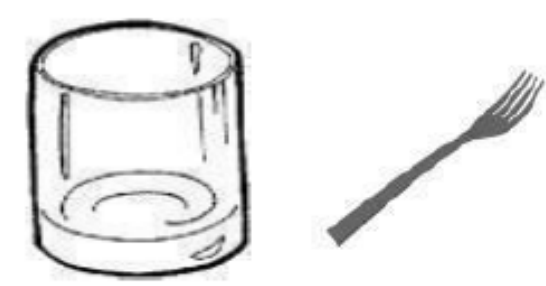

szklanka/un verre
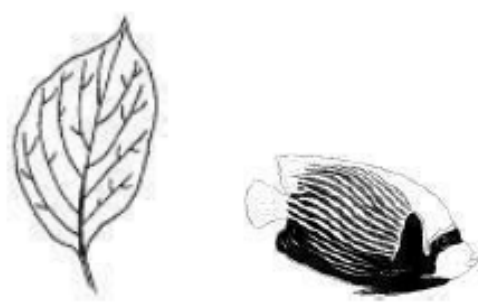

widelec/une fourchette liść/une feuille

ryba/un poisson

Figure 1. A few examples of images used in Experiment 1 and their names in Polish and in French. Images were presented to participants without captions.

\section{Procedure}

Each participant received an envelope with 19 images and a sheet of paper with instructions (either in Polish or in French), and were asked to open the envelope and read the instructions. The instructions were provided in the subjects' native language, and they can be roughly translated to English as: 
We have an idea for a film in which the characters - animate objects and animals - talk to each other. You will see a series of images depicting our "actors." We would like to ask you to decide what type of voice each of them should speak in - a male voice, or a female voice. Circle the letter "M" next to an image (if you choose a male voice) or "F" (if you choose a female voice).

The study was conducted one-on-one, without a time limit. At the end of the experiment, each participant was asked to caption each of the images: Now next to each of the images write one word describing it. This was done to check the word to which the assigned voice refers, and to make sure that each of the participants defined the objects in the same way. This was necessary to keep the conditions of the procedure uniform. The participants were unanimous in naming the objects depicted in the images. The instructions in their original languages can be found in Annex A.

Table 1. Names of objects depicted in the images, in Polish and in French, divided into "artificial" and "natural" categories, as well as their English translations. Each word has opposite grammatical gender in the two languages

\begin{tabular}{|c|c|c|c|c|c|}
\hline & Poli & & Frenc & & English translation \\
\hline \multirow{10}{*}{ Artificial } & samochód & \multirow{5}{*}{$\begin{array}{l}\text { Masculine } \\
\text { (m) }\end{array}$} & une voiture & \multirow{5}{*}{$\begin{array}{l}\text { Feminine } \\
\text { (f) }\end{array}$} & a car \\
\hline & dzwon & & une cloche & & a bell \\
\hline & stół & & une table & & a table \\
\hline & widelec & & une fourchette & & a fork \\
\hline & zegarek & & une montre & & a watch \\
\hline & książka & & un livre & & a book \\
\hline & torba & & un sac & & a bag \\
\hline & łódka & Feminine & un bâteau & Masculine & a boat \\
\hline & ciężarówka & & un camion & & a truck \\
\hline & szklanka & & un verre & & a glass \\
\hline & pomidor & & une tomate & & a tomato \\
\hline & liść & & une feuille & & a leaf \\
\hline & księżyc & Masculine & la lune & Feminine & a moon \\
\hline & banan & & une banane & & a banana \\
\hline Natural & żółw & & une tortue & & a turtle/a tortoise \\
\hline & chmura & & un nuage & & a cloud \\
\hline & ryba & Feminine & un poisson & Masculine & a fish \\
\hline & cytryna & (f) & un citron & (m) & a lemon \\
\hline & małpa & & un singe & & a monkey/an ape \\
\hline
\end{tabular}




\section{Results}

A Logistic Generalised Linear Mixed Model regression (Logistic GLMM) was conducted on the data. This model contained as fixed effects: (a) the language spoken by the subject (French or Polish; French was reference level), (b) the grammatical gender of the objects according to Polish grammar (masculine or feminine; Polish masculine grammatical gender was reference level), (c) the interaction between these two predictors, (d) the object type (natural or artificial; artificial was reference predictor), and (e) the interaction between object type and native language.

Additionally, three random effects were included: by-subject and by-object random intercepts and random slopes estimating effect of country variating between objects. The outcome variable was the subject's decision to attribute a male or female voice to the presented object. Random effects allowed for the control of variation caused by choosing samples from an infinite population of objects or subjects. This allows the results of this analysis to be generalized to other participants and other items.

The primary model, which used all of the factors, revealed that type of object (artificial vs natural) was the only non-significant predictor of the tendency to assign a male or female voice to an object. To simplify interpretation of the results, the next model included only the significant predictors (Language * GG).

Table 2. Results of Logistic GLMM

\begin{tabular}{cccccr}
\hline & $\boldsymbol{\beta}$ & $\boldsymbol{S E}$ & $\boldsymbol{Z}$ & $\boldsymbol{p}$ & \multicolumn{1}{c}{$\boldsymbol{e}^{(\boldsymbol{\beta})}$} \\
\hline (Intercept) & $\mathbf{- 1 . 5 7}$ & $\mathbf{0 . 3 1}$ & $\mathbf{- 5 . 1 3}$ & $<\mathbf{0 . 0 0 1}$ & $\mathbf{0 . 2 1}$ \\
GG: Feminine & $\mathbf{- 2 . 6 2}$ & $\mathbf{0 . 3 5}$ & 7.47 & $<\mathbf{0 . 0 0 1}$ & $\mathbf{1 3 . 7 3}$ \\
Language: Polish & $\mathbf{2 . 0 2}$ & $\mathbf{0 , 2 5}$ & $\mathbf{7 . 9 5}$ & $<\mathbf{0 . 0 0 1}$ & $\mathbf{7 . 5 2}$ \\
Artificial/Natural & 0.17 & 0.35 & 0.49 & 0.62 & 1.19 \\
GG: Feminine: *Language: Polish & $\mathbf{4 . 8 3}$ & $\mathbf{0 . 3 7}$ & $\mathbf{- 1 3 . 0 8}$ & $<\mathbf{0 . 0 0 1}$ & $\mathbf{1 2 5 . 6 4}$ \\
Language: Polish * Type: Natural & -0.13 & 0.36 & -0.37 & 0.72 & 0.88 \\
\hline Note: $\beta$ - regression coefficient; SE - Standard Error; Z- standard score, $\mathrm{p}$ - significance value; $\mathrm{e}^{(\beta)}-$ odds \\
ratio
\end{tabular}

Given that language and GG (grammatical gender) are meaningless as individual predictors, only the interaction effect was described. If Polish speakers were asked to assign a gender to a word, they were more likely to assign a female voice to a feminine word than a female voice to a masculine word by a factor of the odds ratio $\exp (4.83-2.82)=7.46$. French-speaking subjects did the same with an even bigger odds ratio of $\exp (2.63)=13.74$. This means that when assigning a voice to an object, they were 13.74 times more likely to assign a female voice to an object whose name's grammatical gender was feminine than to one whose grammatical gender was masculine. In other words, as shown in Table 3, the probability of assigning a female voice to 
an object with feminine grammatical gender in French and masculine in Polish by a French speaker equals $76 \%$, and it's only $18 \%$ if a word has masculine grammatical gender in French.

Table 3. Log odds for interaction of grammatical gender and country of origin

\begin{tabular}{cccc}
\hline L1 & $\begin{array}{c}\text { Grammatical } \\
\text { gender in } \\
\text { Polish }\end{array}$ & $\begin{array}{c}\text { Grammatical } \\
\text { gender in L1 }\end{array}$ & $\begin{array}{c}\text { Log-odds (Probability that subject from } \\
\text { given country will assign female voice to } \\
\text { word of given grammatical gender in Polish) }\end{array}$ \\
\hline French & Masculine & Feminine & $1.13=1.13(76 \%)$ \\
French & Feminine & Masculine & $1.13-2.63=-1.50(18 \%)$ \\
Polish & Masculine & Masculine & $1.13-2.82=-1.69(16 \%)$ \\
Polish & Feminine & Feminine & $1.13-2.82-2.63+4.83=0.51(62 \%)$ \\
\hline
\end{tabular}

Table 4. Results of final GLMM

\begin{tabular}{cccccc}
\hline & $\beta$ & $S E$ & $Z$ & $p$ & $e^{(\beta)}$ \\
\hline (Intercept) & 1.13 & 0.23 & 4.85 & $<0.001$ & 3.10 \\
Language: Polish & -2.82 & 0.27 & -10.62 & $<0.001$ & 0.06 \\
GG: Feminine & -2.63 & 0.35 & -7.47 & $<0.001$ & 0.07 \\
$\begin{array}{c}\text { Language: Polish * GG: } \\
\text { Feminine }\end{array}$ & 4.83 & 0.37 & 13.09 & $<0.001$ & 125.81 \\
\hline
\end{tabular}

Note: $\beta$ - regression coefficient; SE - Standard Error; $\mathrm{Z}$ - standard score, $\mathrm{p}$ - significance value; $\mathrm{e}^{(\beta)}-\mathrm{odds}$ ratio

To get a better sense of this, frequency graphs of the assignment of a female voice to particular objects are presented in Figure 2.

\section{Discussion}

The first experiment confirmed the first hypothesis. A female voice was more frequently assigned to pictures depicting objects with feminine grammatical gender, and a male voice was more frequently assigned to those that have male grammatical gender. Some objects deviate from this general tendency. For instance, more than half of the French-speakers assigned a male voice to the grammatically female "banana." Polish-speaking participants did not have any particular doubts in this case, which is unsurprising since "banana" is of masculine grammatical gender in Polish. This suggests that when attributing masculine or feminine features to objects, apart from their grammatical gender, participants may also be guided some confounding variables that were unaccounted for in the experimental design. The second hypothesis, concerning the more frequent ascription of feminine features to natural objects, was not confirmed. 


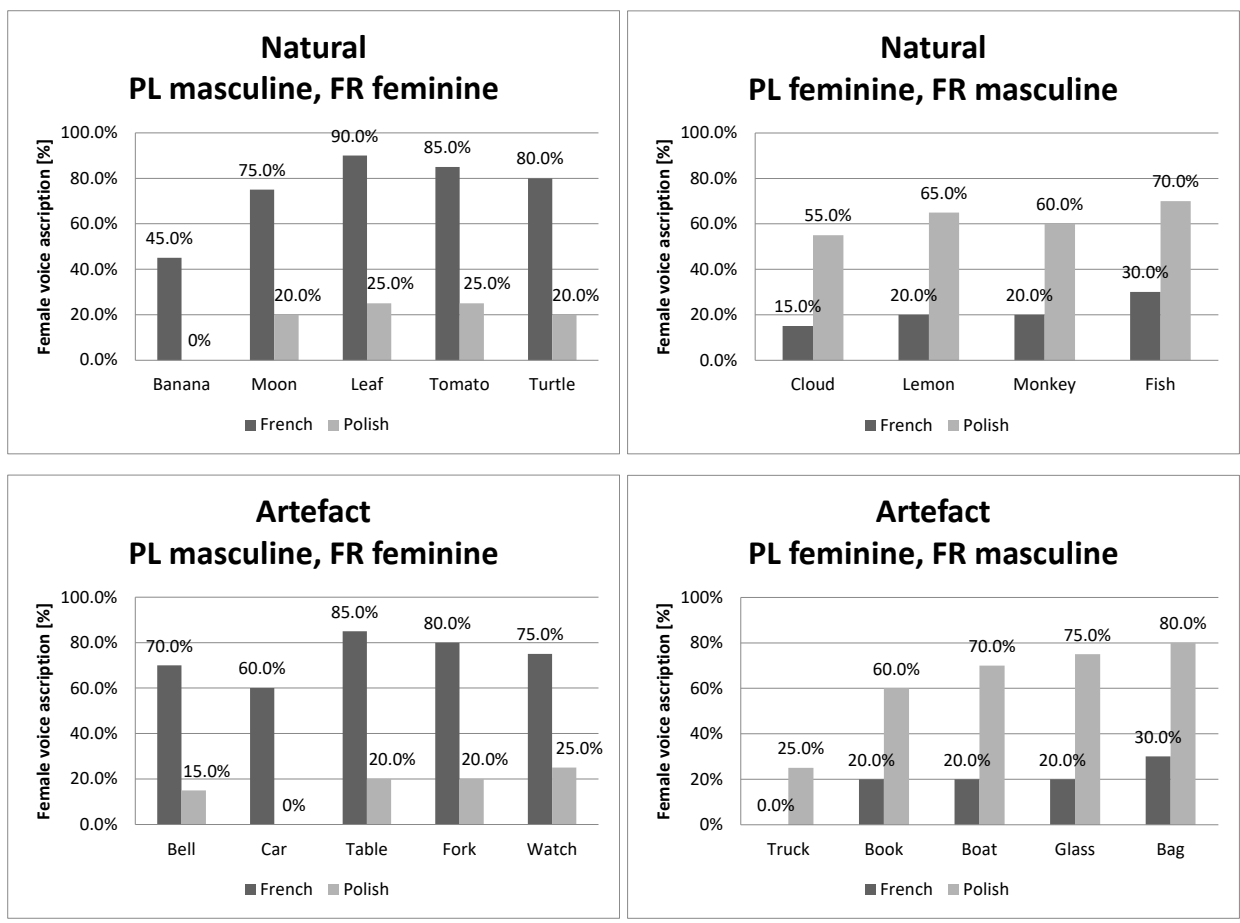

Figure 2. Frequency of assigning a female voice to objects by Polish and French speakers.

\section{Experiment 2}

In the second experiment, the same participants were asked to assign three adjectives from a list to each of 12 presented nouns (artifacts and natural objects). Each of the adjectives referred to either a stereotypically male or stereotypically female feature (Bem, 1993). The procedure was chosen to make sure that assignment was done through conceptual attribution, because the concept of grammatical gender was not expressed explicitly.

\section{Materials and procedure}

Materials for participants from the two groups were in their native language. Each participant was given a sheet of paper with instructions on the top, a column of 12 nouns on the left side (artifacts and natural objects, with equal numbers of masculine and feminine words, their grammatical genders different in the two languages), and a column of 24 adjectives on the left side. The nouns were mixed such that the distinction between groups (artifacts/natural objects, masculine nouns/feminine nouns) was not obvious to the participants, and so they would not be cued by this distinction. The adjectives presented to the participants expressed features that were stereotypically feminine and masculine, based on those described by Bem (1993) as well as those used by Kuczyńska (1992) in 
her Inventory for assessing psychological gender. The method used in this study and the results were in line with the study of C.L. Martin (1987), conducted in the USA.

Each participant received the nouns and adjectives in a different order to eliminate potential effects of confounding variables. Table 5 presents a list of nouns divided into groups (artificial/natural, feminine/masculine). Table 6 shows a list of adjectives used in the study, with a distinction between those that express stereotypically feminine and masculine features.

Table 5. List of nouns with opposite grammatical genders in Polish and in French, as well as their English translations, divided into "artificial" and "natural" categories, and subdivided into masculine and feminine nouns

\begin{tabular}{|c|c|c|c|c|c|}
\hline & \multicolumn{2}{|c|}{ Polish } & \multicolumn{2}{|c|}{ French } & \multirow{2}{*}{$\frac{\text { English translation }}{\text { a house }}$} \\
\hline \multirow{6}{*}{ Artificial } & dom & & une maison & & \\
\hline & stół & masculine & une table & feminine & a table \\
\hline & dzwon & & une cloche & & a bell \\
\hline & książka & & un livre & & a book \\
\hline & kanapa & feminine & un canapé & masculine & a sofa \\
\hline & ściana & & un mur & & a wall \\
\hline \multirow{6}{*}{ Natural } & księżyc & & la lune & & a moon \\
\hline & deszcz & masculine & la pluie & feminine & a rain \\
\hline & las & & une forêt & & a forest \\
\hline & pustynia & & un désert & & a desert \\
\hline & chmura & feminine & un nuage & masculine & a cloud \\
\hline & palma & & un palmier & & a palm tree \\
\hline
\end{tabular}

The instructions participants were given can be roughly translated to English as:

For each of the nouns in the column on the right, choose three adjectives from the column on the right (write them next to each noun).It is not obligatory to use all of the adjectives. You can use the same adjective more than once.

There was no time limit for the task. As in the case of Experiment 1, Experiment 2 was conducted in a one-on-one setting.

\section{Results}

A Logistic Generalised Linear Mixed Model regression was conducted on the data. This model contained as fixed effects: (a) the language spoken by the subject (French or Polish; French was reference level), (b) the grammatical gender of the objects according to polish grammar (masculine or feminine; Polish masculine grammatical gender was reference level) (c), the interaction between 
these two predictors, (d) object type (natural or artificial, artificial was reference predictor), and (e) the interaction between object type and native language.

Table 6. List of adjectives in Polish and in French describing stereotypically masculine and feminine features

\begin{tabular}{cccc}
\hline Polish & French & English translation \\
\hline chłodny/a & froid/e & cold \\
silny/a & fort/e & strong \\
surowy/a & sévère & strict \\
ambitny/a & ambitieux/se & ambitious \\
niezależny/a & indépendant/e & independent \\
imponujący/a & impressionnant/e & impressive \\
rządzący/a & dirigeant/e & ruling \\
odważny/a & courageux/se & courageous \\
dominujący/a & dominant/e & dominating \\
odporny/a & résistant/e & resistant \\
aktywny/a & actif/ve & active \\
przedsiębiorczy/a & entreprenant/e & enterprising \\
słaby/a & faible & weak \\
bierny/a & passif/ve & passive \\
łagodny/a & doux/ce & gentle \\
ciepły/a & chaud/e & warm \\
nieśmiały/a & timide & shy \\
estetyczny/a & esthétique & aesthetic \\
delikatny/a & délicat/e & delicate \\
uroczy/a & charmant/e & charming \\
zależny/a & dépendant/e & dependent \\
uległy/a & soumis/e & submissive \\
kruchy/a & beau/belle & beautiful \\
& & fragile & fragile \\
\hline & &
\end{tabular}

Additionally, three random effects were included: by-subject and by-object random intercepts and random slopes estimating effect of country variating between objects. The outcome variable was the subject's decision to attribute more male or female features to an item (data were categorized based on whether at least 2 out of 3 of the chosen adjectives were stereotypically male/female). The random effects allowed for controlling variation caused by choosing a limited sample from an infinite population of items (words) or potential participants. This allows the results of this analysis to be generalized to other participants and other items. 
The primary model, consisting of all of the factors, revealed that only the interaction of language and the item's grammatical gender was a significant predictor. To simplify the interpretation of results, the next model included only the significant predictors (Language* $\mathrm{GG}$ ).

Table 7. Results of Logistic GLMM

\begin{tabular}{cccccc}
\hline & $\boldsymbol{\beta}$ & $\boldsymbol{S E}$ & $\boldsymbol{Z}$ & $\boldsymbol{p}$ & $\boldsymbol{e}^{(\boldsymbol{\beta})}$ \\
\hline (Intercept) & -0.29 & 0.25 & -1.15 & 0.25 & 0.75 \\
Language: Polish & 0.21 & 0.27 & 0.78 & 0.44 & 1.23 \\
GG: Feminine & -0.27 & 0.31 & 0.88 & 0.38 & 0.76 \\
Type: Natural & 0.16 & 0.23 & 0.69 & 0.49 & 1.17 \\
$\begin{array}{c}\text { Language: Polish * GG: } \\
\text { Feminine }\end{array}$ & $\mathbf{0 . 8 2}$ & $\mathbf{0 . 3 8}$ & $\mathbf{- 2 . 1 9}$ & $<\mathbf{0 . 0 5}$ & $\mathbf{2 . 2 8}$ \\
$\begin{array}{c}\text { Language: Polish * Type: } \\
\text { Natural }\end{array}$ & -0.21 & 0.38 & -0.55 & 0.59 & 0.81 \\
\hline
\end{tabular}

Note: $\beta$ - regression coefficient; $\mathrm{SE}$ - Standard Error; $\mathrm{Z}$ - standard score, $\mathrm{p}$ - significance value; $\mathrm{e}^{(\beta)}$ - odds ratio

Given that language and GG (grammatical gender) are meaningless as individual predictors, only the interaction effect was described. If Polish speakers were asked to attribute features to a word, they were more likely to attribute female features to a feminine word than female features to a masculine word by a factor of the odds ratio $\exp (0.82-0.27)=1.73$. In turn, the French-speakers made the same characterization with a lower odds ratio of $\exp (0.27)=1.31$. In other words, if French speakers were asked to attribute features to a given item, they were 1.31 times more likely to attribute female features to items with feminine grammatical gender in contrast to items with male grammatical gender. According to Table 9, the probability of attributing female features to words with feminine gender in French by French speakers is 45\%, and it's 38\% if a word has masculine gender in French.

Table 8. Results of final Logistic GLMM

\begin{tabular}{cccccc}
\hline & $\boldsymbol{\beta}$ & $\boldsymbol{S E}$ & $\boldsymbol{Z}$ & $\boldsymbol{p}$ & $\boldsymbol{e}^{(\boldsymbol{\beta})}$ \\
\hline (Intercept) & -0.21 & 0.23 & -0.91 & 0.36 & 0.81 \\
Language: Polish & 0.21 & 0.27 & 0.78 & 0.44 & 1.23 \\
GG: Feminine & -0.27 & 0.32 & 0.86 & 0.39 & 1.32 \\
$\begin{array}{c}\text { Language: Polish \& GG: } \\
\text { Feminine }\end{array}$ & 0.82 & 0.38 & -2.18 & 0.03 & 0.44 \\
\hline
\end{tabular}

Note: $\beta$ - regression coefficient; $\mathrm{SE}$ - Standard Error; $\mathrm{Z}$ - standard score, $\mathrm{p}$ - significance value; $\mathrm{e}^{(\beta)}-$ odds ratio 
Table 9. Log odds for interaction of grammatical gender and country of origin

\begin{tabular}{cccc}
\hline L1 & $\begin{array}{c}\text { Grammatical } \\
\text { gender in } \\
\text { Polish }\end{array}$ & $\begin{array}{c}\text { Grammatical } \\
\text { gender in L1 }\end{array}$ & $\begin{array}{c}\text { Log-odds (Probability that subject from } \\
\text { given country will assign female voice to } \\
\text { word of given grammatical gender in Polish) }\end{array}$ \\
\hline French & Masculine & Feminine & $-0.21=-0.21(45 \%)$ \\
French & Feminine & Masculine & $-0.21-0.27=-0.48(38 \%)$ \\
Polish & Masculine & Masculine & $-0.21+0.21=0(50 \%)$ \\
Polish & Feminine & Feminine & $-0.21+0.21-0.27+0.82=0.55(63 \%)$ \\
\hline
\end{tabular}

To get a better sense of this, graphs of the frequency of assignment of a female voice to particular items are presented in Figure 3.

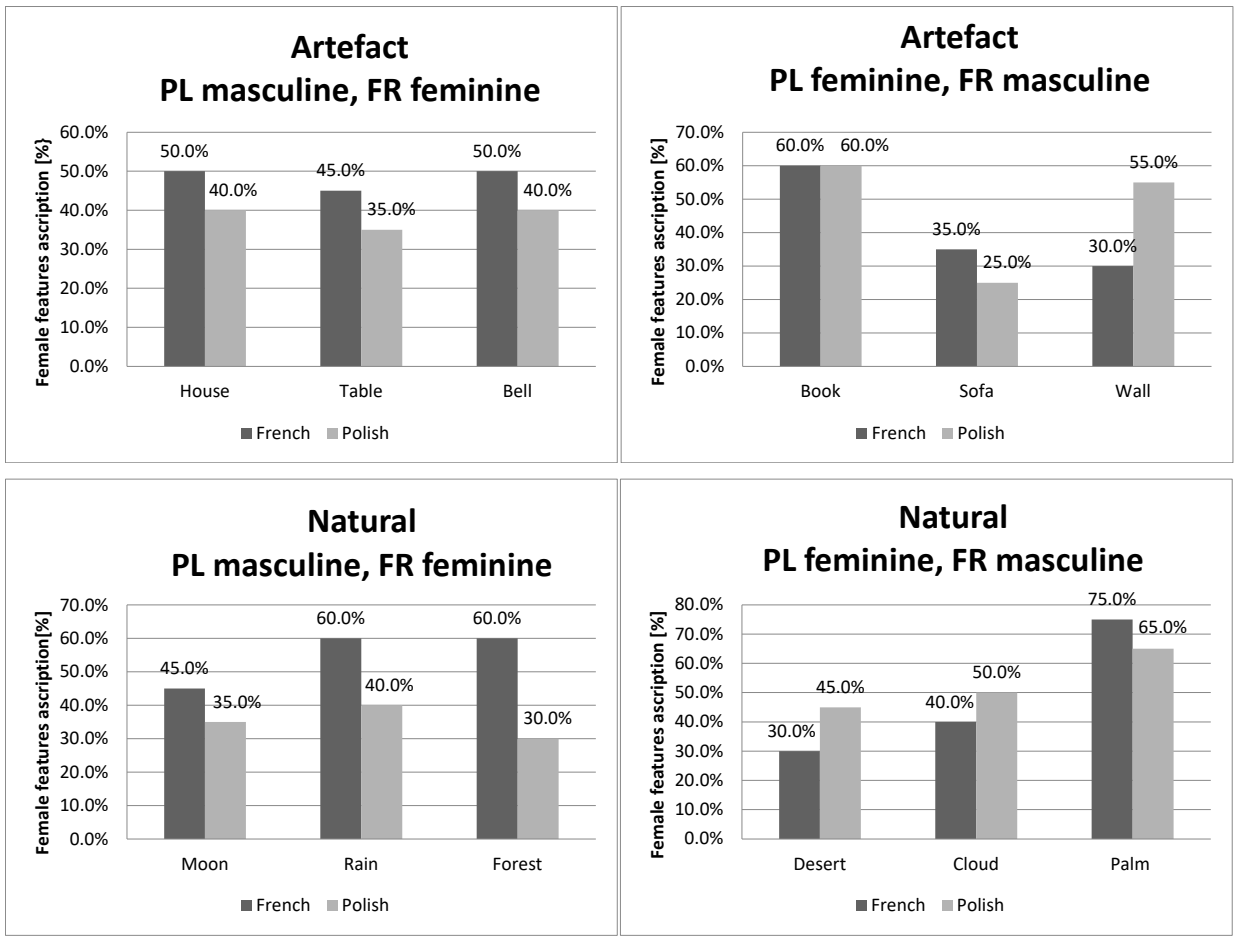

Figure 3. Frequency of attribution of female adjectives to objects by Polish and French speakers..

\section{Discussion}

In this experiment, the first hypothesis, that Polish and French speakers will ascribe masculine and feminine features to items in congruence with grammatical gender, was confirmed. Subjects more frequently chose adjectives whose stereotypical associations with masculinity and femininity were congruent with the grammatical gender of the noun. These results are in line with previous research. However, as in the first experiment, there were also some words that exhibited deviations from this general tendency - e.g. $75 \%$ of French-speakers 
attributed feminine features to the item 'palm tree' even though it had masculine grammatical gender in French. Again, the second hypothesis was not confirmed, i.e. there were no differences in the frequency with which feminine features were attributed to nouns that referred to natural objects and artifacts.

\section{General Discussion}

Our results confirming the first hypothesis, that masculine and feminine features are ascribed to objects in congruence with their grammatical gender, are in line with the findings of Sera, Berge, \& del Castillo Pintado (1994) and Boroditsky \& Phillips (2003). Thus, it can be said that in this regard these studies have been replicated on Polish and French speaking samples, which speaks in favour of the belief that grammatical gender influences the perception of objects. Moreover, the replication of the experiment of Boroditsky \& Phillips (2003) was done in a setting where subjects were less likely to be able to directly rely on linguistic cues. This makes the results more robust. In their experiment, subjects were explicitly asked to assess nouns on scales of femininity and masculinity. Here, subjects were asked to associate them with properties that are stereotypically considered feminine or masculine (Bem, 1993).

However, the second hypothesis, concerning supra-language semantic rules influencing the perception of gender of objects, such that feminine features would be attributed more often to natural objects than to artifacts, was not confirmed in either of our experiments. This is in line with Foundalis's (2002) criticism of the research of Boroditsky and Schmidt (2000).

One could speculate, however, that the deviations from the first hypothesis could somewhat be in support of the second hypothesis. The special cases, which do not follow the patterns characteristic to their grammatical gender, could in fact be subject to more general, supra-language semantic rules. Though it is impossible to infer from just a pair of languages, it could be worth further investigating whether such words follow a similar pattern across multiple languages. It also needs to be noted that the fact that words chosen for the study were such that their grammatical gender was different in the two languages may, in itself, mean that in the case of these particular words, grammatical gender is more arbitrary than in others. Thus the design, which in one way was supposed to facilitate the investigation of the second hypothesis by limiting one type of bias, could have hindered this endeavour by introducing a different bias.

Thus, whether grammatical gender is entirely arbitrary is still an open question. In a study comparing some Indo-European languages, Foundalis (2002) tried to show that grammatical gender is entirely arbitrary, and the only possible relationship occurs in closely related languages. However, it is worth noting that despite the fact that many of the correlations between grammatical gender in Indo-European languages were very weak, there was not a single negative correlation. Another thing worth noting is that in both Foundalis's study and the 
one he criticizes, the sample of words was relatively small (about 80 nouns). It would definitely be conceivable to perform, and interesting to see, such analyses for much larger samples of nouns, of a comparable order to the number of nouns that can actually exist in a language. Considering that, say, English has tens of thousands of nouns, the samples used in the two aforementioned studies may be too small.

\section{Limitations}

This study, like similar studies (e.g. Boroditsky \& Phillips, 2003), has a relatively small sample size. It would be useful to attempt to replicate such studies with larger samples, so that the results would be more reliable and more generalisable. Though it should be noted that the GLMM analyses used in this study can be considered a strength - they make the results more generalisable than results obtained on similar sample sizes and then analysed with simpler methods (e.g. Student t-test). Though GLMM analyses are becoming increasingly popular in psycholinguistics, they were often not used in previous similar studies (e.g. Boroditsky \& Phillips, 2003).

However, another important thing that ought to be noted is the fact that even in the experiments designed to eliminate explicit linguistic cues, one cannot be sure that subjects did not make use of them. It could be that in the absence of other cues, some subjects consciously chose a strategy to refer to the grammatical gender of the names of the objects. In future studies, researchers could consider asking subjects some follow-up questions after completing all of the experiments, regarding the strategies implemented when performing a task.

\section{Conclusions}

This study replicated the finding that masculine and feminine features are frequently ascribed to objects in congruence with their grammatical gender, which is evidence of the impact of grammatical gender on perception. The results did not support the idea of a supra-language conceptual gender categorisation of objects, though it cannot be said that this finding is conclusive. It should be noted that the relationship between language and thought is in no way simple, and nowadays it is believed that there are many complex mechanisms behind the relationship between cognitive processes and language systems (Rączaszek-Leonardi, 2011). While only a narrow section of this broad problem was investigated in this paper, it nonetheless sheds some light on the subject. 


\section{Acknowledgements}

I would like to thank the reviewers for comments that proved very valuable in the process of writing the manuscript, Professor Joanna Raczaszek-Leonardi of the University of Warsaw, Poland for inspiration and important advice, Monika Folkierska-Żukowska, of the University of Warsaw, Poland, for translation and substantial help in revising the manuscript, Łukasz Rąbalski for methodological support and my husband Adam Haertlé for his encouragement and support.

\section{References}

Athanasopoulos, P., Bylund, E., Casasanto D. (2016). Introduction to the Special Issue: New and Interdisciplinary Approaches to Linguistic Relativity. Language Learning, 66(3), 482-486. doi:10.1111/lang.12196

Athanasopoulos, P., Bylund, E., Montero-Melis, G., Damjanovic, L., Schartner, A., Kibbe, A., Riches, N., Thierry, G. (2015) Two languages, two minds: Flexible cognitive processing driven by language of operation. Psychological Science, 26(4). 518-526. doi:10.1177/0956797614567509

Bem, S. L. (1993). The lenses of gender: Transforming the debate on sexual inequality. New Haven, CT: Yale University Press.

Boroditsky, L. (1999). First-language thinking for second-language understanding: Mandarin and English speakers conception of time. In M. Hahn, S. Stoness (Eds.), Proceedings of the Twenty-First Annual Conference of the Cognitive Science Society, 21 (pp. 84-89). Vancouver.

Boroditsky, L. (2000). Metaphoric structuring: Understanding time through spatial metaphors. Cognition, 75, 1-28. doi:10.1016/s0010-0277(99) 00073-6

Boroditsky, L. (2001). Does language shape thought? Mandarin and English speakers conceptions of time. Cognitive Psychology, 43(1), 1-21. doi:10.1006/cogp.2001.0748

Boroditsky, L., Gaby, A. (2010). Remembrances of times east: Absolute spatial representations of time in an Australian Aboriginal Community. Psychological Science, 21(11), 1635-1639. doi:10.1177/0956797610386621

Boroditsky, L., Ham, W., Ramscar, M. (2002). What is universal about event perception? Comparing English and Indonesian speakers. In W. D. Gray, C.D. Schunn. (Eds.), Proceedings of the 24th Annual Meeting of the Cognitive Science Society (pp. 136-141). Fairfax, VA: Cognitive Science Society. doi:10.1111/1467-9280.00434

Boroditsky, L., Phillips, W. (2003). Can Quirks of Grammar Affect the Way You Think? Grammatical Gender and Object Concepts. In R. Alterman, D. Kirsh (Eds.), Proceedings of the 25th Annual Meeting of the Cognitive Science Society (pp. 928-933). Boston, MA: Cognitive Science Society. 
Boroditsky, L., Schmidt, L. (2000). Sex, syntax and semantics. In L. R., Gleitman, A. K. Joshi, (Eds.), Proceedings of the 22nd Annual Meeting of the Cognitive Science Society (pp. 42-46). Philadelphia, PA: Cognitive Science Society.

Boutonnet, B., Athanasopoulos, P., Thierry, G. (2012). Unconscious effects of grammatical gender during object categorization. Brain Research, 1479, 72-79. doi:10.1016/j.brainres.2012.08.044

Bowerman, M., Choi, S., McDonough, L., Mandler, J. (1999). Comprehension of spatial terms in English and Korean. Cognitive Development, 14, 241-268. doi:10.1016/S0885-2014(99)00004-0

Choi, S. (2009).Typological differences in syntactic expressions of path and causation. In V. Gathercole (Ed.), Routes to Language: Studies in Honor of Melissa Bowerman (pp. 169-194), Mahwah, NJ: Lawrence Erlbaum Associates.

Cubelli, R., Paolieri, D., Lotto, L., Job, R. (2011). The effect of grammatical gender on object categorisation. Journal of Experimental Psychology: Learning, Memory and Cognition, 37(2), 449-460. doi:10.1037a0021965

Czechowska, N., Ewert, A. (2011) Perception of motion by Polish-English bilinguals. In V.Bassetti, B. Cook (Eds.), Language and Bilingual Cognition (pp. 287-314), New York, NY: Psychology Press.

Ervin, S. M. (1962). The connotations of gender. Word, 18, 249-261.

Fausey C., Boroditsky, L. (2010). Subtle linguistic cues influence perceived blame and financial liability. Psychonomic Bulletin \& Review, 17(5), 644-650.

Fausey C., Boroditsky L. (2011).Who dunnit? Cross-linguistic differences in eye-witness memory. Psychonomic Bulletin \& Review, 18(1), 150-157. doi: 10.3758/s13423-010-0021-5

Fausey C., Long, B., Inamori, A., Boroditsky L. (2010a). Constructing agency: the role of language. Frontiers in Psychology, 1, 162. doi:10.3389/ fpsyg. 2010.00162

Foundalis, H. E. (2002). Evolution of gender in Indo-European languages. In W. D. Gray, C. Schunn (Eds.), Proceedings of the 24th Annual Meeting of the Cognitive Science Society (pp. 304-309). Fairfax, VA: Cognitive Science Society.

Gentner, D. \& Loftus, E.F. (1979) Integration of verbal and visual information as evidenced by distortions in picture memory. American Journal of Psychology, 92(2), 363-375. doi:10.2307/1421930

Gopnik, A., Choi, S. (1995). Names, relational words and cognitive development in English and Korean Speakers: Nouns are not always learned before verbs. In M. Tomasello, W. Merriman (Eds.), Beyond names for things: Young children's acquisition of verbs (pp. 63-80). New Jersey, NJ: Erlbaum.

Konishi, T (1993). The semantics of grammatical gender: A cross-cultural study. Journal of Psycholinguistic Research, 22, 519-534. doi:10.1007/ BF01068252 
Kuczyńska, A. (1992). Inwentarz do oceny ptci psychologicznej. [Inventory for assessing psychological gender] Warszawa: Pracownia Testów Psychologicznych Polskiego Towarzystwa Psychologicznego.

Lakoff, G., Johnson, M. (1980). Metaphors We Live By. Chicago and London: The University of Chicago Press. doi:10.1207/s15516709 $\operatorname{cog} 0402 \_4$

Landau, B., Jackendoff, R. (1993) 'What' and 'Where' in spatial language and spatial cognition. Behavioural and Brain Sciences, 16, 217-238. doi: 10.1017/S0140525X00029733

Leavitt, J. (2014). Linguistic relativity: Precursors and transformations. In F. Sharifan (Ed.), The Routledge Handbook of Language and Culture (pp. 18-30). London: Routledge.

Levinson, S. C., Kita, S., Haun, D. B., Rasch, B. H. (2002) Returning the tables: Language affects spatial reasoning. Cognition, 84(2), 155-188. doi:10.1016/ S0010-0277(02)00045-8

Loftus, E. F. \& Palmer, J.C. (1974) Reconstruction of automobile destruction: An example of the interaction between language and memory. Journal of Verbal Learning and Verbal Behavior, 13, 585-589. doi:10.1016/S00225371(74)80011-3

Lucy, J. A. (2016). Recent advances in the study of linguistic relativity in historical context: A critical assessment. Language Learning, 66(3), 487-515. doi : 10.1111/lang.12195

Martin C. L. (1987). Ratio measure of sex stereotyping. Journal of Personality and Social Psychology, 3, 489-499. doi:10.1037/0022-3514.52.3.489

McDonough, L.,Choi, S., Mandler, J.M. (2003) Understanding spatial relations: flexible infants, lexical adults. Cognitive Psychology, 46(3), 229-259. doi:10.1016/S0010-0285(02)00514-5

Mullen, M. K. (1990). Children's Classification of Nature and Artifact Pictures into Female and Male Categories. Sex Roles, 23(9/10), 577-587. doi:10.1007/ BF00289769

Ortner, S. B. (1974). Is female to male as nature is to culture? In M. Rosaldo, L. Lamphere (Eds.), Woman, culture and society (pp. 67-87). Stanford, CA: Stanford Press.

Pavlenko A. (2016). Whorf's lost argument: Multilingual awareness. Language Learning, 66(3), 581-607. doi:10.1111/lang.12185

Rączaszek-Leonardi, J. (2010). Multiple time-scales of language dynamics: An example from psycholinguistics. Ecological Psychology, 22(4), 269-285. doi:10.1080/10407413.2010.517111

Rączaszek-Leonardi J. (2011). Zjednoczeni w mowie. Względność językowa w ujęciu dynamicznym. Warszawa: Wydawnictwo Naukowe Scholar.

Rhode, A.K. Voyer, B.V., Gleibs, I.H. (2016). Does language matter? Exploring Chinese-Korean differences in holistic perception. Frontiers in Psychology, 7. doi:10.3389/fpsyg.2016.01508 
Sapir, E. (1929). The status of linguistics as a science. In D. G. Mandelbaum (Ed.), Culture, Language and Personality (pp. 65-77). Berkeley, CA: University of California Press, 1958.

Scholl, B. J., Nakayama, K. (2002) Casual capture: contextual effects on the perception of collision events. Psychological Science, 13, 493-498. doi:10.1111/1467-9280.00487

Sera, M. D., Berge, C., del Castillo Pintado, J. (1994). Grammatical and conceptual forces in the attribution of gender by English and Spanish Speakers. Cognitive Development, 9, 261-292. doi:10.1016/0885-2014(94)90007-8

Thierry, G., Athanasopoulos, P., Wiggett, A., Dering, B., Kuipers, J. (2009). Unconscious effects of language-specific terminology on pre-attentive colour perception. Proceedings of the National Academy of Sciences, 106, 4567-4570. doi:10.1073/pnas.0811155106

Thierry, G. (2016). Neurolinguistic relativity: How language flexes human perception and cognition. Language Learning, 66(3), 690-713. doi: 10.1111/lang. 12186

Vigliocco, G., Vinson, D. P., Paganelli, F., Dworzynski, K. (2005). Grammatical gender effects on cognition: Implications for language learning and language use. Journal of Experimental Psychology: General, 134, 501-520. doi:10.1037/0096-3445.134.4.501

Whorf, B. L., Carroll J. B. (1956). Language, thought and reality: Selected writings. MIT Press.

Winawer, J., Witthoft, N., Frank, M., Wu, L., Wade, A., Boroditsky, L. (2007) Russian blues reveal effects of language on color discrimination. Proceedings of the National Academy of Sciences, 104, 7780-7785. doi:10.1073/ pnas.0701644104 


\section{Annex A}

\section{Instructions for Experiment 1}

Polish version:

Mamy pomyst nakręcenia filmu, w którym postaci - ożywione przedmioty oraz zwierzęta - rozmawiaja ze sobą. Zobaczysz za chwilę serię obrazków przedstawiajacych naszych aktorów. Prosimy Cię o zdecydowanie, jakim głosem powinien mówić każdy z nich-głosem mężczyzny, czy też kobiety. Obok każdego obrazka otocz kółkiem literkę M (jeśli wybierasz głos męski) lub K (jeśli wybierasz głos kobiecy).

French version:

On a l'idée de tourner un film où les personnages - des objets qui deviennent vivants et des animaux, bavardent ensemble. Vous allez voir les images avec nos " acteurs » et vous êtes prié de décider quelle voix selon vous devrait-on attribuer à chacun d'eux - voix d'homme ou de femme. A côté de chaque image, entourez s'il vous plaît la lettre $M$ (si vous êtes pour la voix masculine) ou F (si vous choisissez la voix féminine).

Approximate English translation:

We have an idea for a film in which the characters - animate objects and animals - talk to each other. You will see a series of images depicting our "actors." We would like to ask you to decide what type of voice each of them should speak in - a male voice, or a female voice. Circle the letter "M" next to an image (if you choose a male voice) or "F" (if you choose a female voice).

If there were problems understanding the instructions, the experimenter explained the task in such a way that its content and the words used would be as close as possible to the written instructions. In situations when the participants expressed uncertainty to the experimenter, the experimenter suggested they use their intuition or their "first association".

\section{Instructions for Experiment 2}

Polish version:

Do każdego rzeczownika z lewej kolumny dopisz po trzy wybrane przymiotniki z prawej kolumny (przepisz je obok każdego rzeczownika). Nie musisz użyć wszystkich przymiotników. Możesz użyć każdego przymiotnika kilkakrotnie. 
French version:

A chaque nom de la colonne de gauche associez trois adjectifs choisis de la colonne de droite (réécrivez-les à côté de chaque nom). Il n'est pas obligatoire d'utiliser tous les adjectifs. Vous pouvez aussi utiliser le même adjectif plusieurs fois.

Approximate English translation:

For each of the nouns in the column on the left, choose three adjectives from the column on the right (write them next to each noun). It is not obligatory to use all of the adjectives. You can use the same adjective more than once.

Raw datasets can be downloaded from https://figshare.com/s/ d3440fb2b12d6a21864d 